\title{
Atorvastatin and Simvastatin, but not Pravastatin, Up-regulate LPS-Induced MMP-9 Expression in Macrophages by Regulating Phosphorylation of ERK and CREB
}

\author{
Dong Kun Lee ${ }^{1}$ Eun Ju Park ${ }^{1}$ Eun Kyoung Kim ${ }^{1} \quad$ JunYup Jin ${ }^{1} \quad$ Jong Soo Kim ${ }^{1}$ Ik Jae \\ Shin $^{2}$ Bo-Yeon Kim² Hookeun Lee ${ }^{3}$ Dong-Eog Kim² \\ ${ }^{1}$ Laboratory of Genome to Drug Medicine, Joint Center for Biosciences, Incheon; ${ }^{2}$ Molecular Imaging \\ and Neurovascular Research Laboratory, Department of Neurology, Dongguk University Ilsan Hospital, \\ Goyang; ${ }^{3}$ College of Pharmacy, Gachon University, 7-45 Songdo-dong Yeonsu-ku, Incheon
}

\section{Key Words}

CREB $・$ ERK $・$ Macrophage $・$ LPS $・$ MMP-9 $・$ Statin

\begin{abstract}
Statins suppress expression of pro-inflammatory cytokines in endothelial cells, whereas they enhance it in immune cells. Pro-inflammatory cytokines and lipopolysaccharide (LPS) induce matrix metalloproteinase (MMP)-9 gene expression in macrophages, which has been linked to progress of various inflammatory diseases. The aim of this study was to identify effects of various statins on LPS-induced MMP-9 gene expression in macrophages and microglia. MMP9 expression was analyzed by real-time PCR or zymography. Effect of statins on activation of signaling pathways was analyzed by time-dependent phosphorylation of signaling molecules. Atorvastatin and simvastatin, but not pravastatin, up-regulated LPS-induced MMP-9 expression in murine RAW 264.7 macrophages and BV2 microglia. The phosphorylation duration of extracellular signal regulated kinases was extended by simvastatin, but not by atorvastatin or pravastatin. The up-regulation of LPS-induced MMP-9 gene expression by the statins was dependent on extracellular calcium ions and mediated by enhancing phosphorylation of CAMP-responsive element binding protein. Geranylgeranyl pyrophosphate, a precursor for cholesterol synthesis, could suppress up-regulation of LPS-mediated MMP-9 gene expression by atorvastatin and simvastatin. Atorvastatin and simvastatin-mediated up-regulation of LPSinduced MMP-9 gene expression in macrophages and microglia in vitro raises an important concern about use of the widely-prescribed statins in certain inflammatory conditions that are mediated by LPS.
\end{abstract}




\section{Introduction}

Matrix metalloproteinase (MMP)-9 may mediate beneficial tissue remodeling during stroke recovery [1]. However, dysregulated expression of MMP-9 in macrophages has been linked to various inflammatory diseases such as atherosclerosis and chronic obstructive pulmonary disease as well as stroke and post-infarct hemorrhagic transformation [26]. The expression level and activity of MMP-9 in macrophages can be up-regulated by lipopolysaccharide (LPS) and proinflammatory cytokines [7].

LPS interacts with Toll-like receptor 4 (TLR4) to function as an endotoxin, and phosphorylates I $\mathrm{KB}$ kinases and mitogen activating protein (MAP) kinases, which induce expression of pro-inflammatory cytokines by activating nuclear factor kappa B (NFKB) and activator protein-1 (AP-1) [8,9]. Sequence analysis of the MMP-9 gene promoter region identified binding sites for AP-1 and NFKB [10]. In addition, LPS has been reported to induce influx of extracellular calcium, which is linked to the activation of calcium ion-dependent transcription factors including nuclear factor of activated T cells or cAMP-responsive element binding protein (CREB) $[11,12]$.

Statins, 3-hydroxy-3-methylglutaryl coenzyme A (HMG-CoA) reductase inhibitors, decrease the incidence of cardiovascular diseases by lowering low-density lipoprotein and triglyceride levels [13]. In addition, statins exert vascular protective effects by inhibiting synthesis of isoprenoids including geranylgeranyl pyrophosphate (GGPP) and farnesyl pyrophosphate, intermediate metabolites of cholesterol synthesis pathway [14]. Inhibition of GGPP-mediated post-translational prenylation of small GTPases has been reported to attenuate NADPH-mediated free radical production $[15,16]$, which modulates MMP-9 gene expression [17].

Although statins have been reported to show pleiotropic beneficial effects with antioxidant and immunomodulation capability $[14,15]$, all statins are associated with myopathy [18]; a disproportionately high incidence of myopathy occurs with high-dose simvastatin [19]. In addition, there is evidence that various statins display mixed metabolic effects ranging from beneficial to adverse effects on insulin resistance [20]. While statins have been reported to decrease expression of proinflammatory cytokines [21, 22] and MMP-9 [23] in endothelial cells, studies using immune cells, such as dendritic cells and macrophages, reported that statins increase expression of pro-inflammatory cytokines [24, 25].

We hypothesized that distinct statins, probably also depending on concentrations, might display differential effects on LPS-induced MMP-9 gene expression in macrophages. Our results demonstrate that various statins show distinct effects on LPS-induced MMP-9 gene expression in macrophages by modulating phosphorylation degrees of MAP kinases and CREB, which are involved in the LPS-mediated signaling pathways. We also investigated if GGPP could affect up-regulation of LPS-induced MMP-9 gene expression in macrophages by the statins.

\section{Materials and Methods}

\section{Reagents}

LPS from E.coli 0111:B4, atorvastatin, pravastatin, simvastatin, TSA, and actinomycin D were purchased from Sigma-Aldrich (St Louis, MO). Primary antibodies against p38, phosphorylated p38, ERK 1/2, phosphorylated ERK 1/2, JNK 1/2, phosphorylated JNK 1/2 which is also known as stress-activated protein kinases, phosphorylated CREB, and beta-tubulin were purchased from Cell Signaling Technology (Danvers, MA). FastStart PCR Master Mixes and phosphatase inhibitor cocktail were purchased from Roche Applied Sciences (Mannheim, Germany). 
Cell culture and treatment

RAW 264.7 murine macrophage cells (purchased from ATCC) and BV2 murine microglia (a generous gift from HS Kim [26]) were maintained in phenol red free DMEM supplemented with $10 \%$ heat-inactivated fetal bovine serum, $100 \mathrm{U} / \mathrm{ml}$ penicillin, and $100 \mu \mathrm{g} / \mathrm{ml}$ streptomycin at $37^{\circ} \mathrm{C}$ in a humidified incubator containing $5 \% \mathrm{CO}_{2}$. In all experiments, cells of less than 27 cell passage number were used. Lipophilic statins, atorvastatin and simvastatin, and TSA were dissolved in dimethylsulfoxide (DMSO) and diluted with cell culture medium just before the treatment. Final concentrations of DMSO in all cell culture experiments were adjusted to $0.05 \%$. Hydrophilic pravastatin was dissolved in PBS.

\section{Synthesis of CDNA and quantitative real-time polymerase chain reaction (PCR)}

When cells in 12 well plates reached 70\% confluency, cells were washed with PBS, incubated in serum-free DMEM, and treated with $0.1 \mu \mathrm{g} / \mathrm{ml}$ LPS from E.coli 0111:B4 and various concentrations of atorvastatin, pravastatin, or simvastatin for $8 \mathrm{~h}$ or $16 \mathrm{~h}$, as indicated. Medium was collected for zymography assay, and total RNA was extracted with TRIsure (Bioline, London, GB) according to the manufacturer's instruction. Synthesis of cDNA was performed using Quantitect Reverse Transcription Kit (Qiagen, Hilden, Germany) according to the manufacturer's instruction. Analysis of mRNA expression was determined with quantitative real-time PCR using FastStart PCR Master Mixes, and 10 pmole primers according to the manufacturer's instruction. The sequences of $\beta$-actin as a reference gene, MMP-9, and MMP- 2 are as follows: $\beta$-actin (forward: 5'-CTAAGGCCAACCGTGAAAAG, reverse: 5'-ACCAGAGGCATACAGGGACA); MMP-9 (forward: 5'-AAACCAGACCCCAGACTCCTC, reverse: 5'-GAGGACACAGTCTGACCTGAA); and MMP-2 (forward: 5'- TCTGGTGCTCCACCACATACAACT, reverse: 5'-CTGCATTGCCACCCATGGTAAACA). Abundance of MMP-9 mRNA in each sample was determined by the $\Delta C \tau$ (cycle threshold), the difference between the $\mathrm{C} \tau$ values for MMP-9 and $\beta$-actin. Relative ratios of MMP-9 mRNA expression levels were defined as $2^{-\Delta \Delta C \tau}$ which reflects changes of MMP-9 expression levels from cells with treatment compared to those from unstimulated cells. All experiments were performed at least 3 times with duplicate samples.

\section{Gelatin zymography}

Aliquots of medium after 16 - 20 h culture were mixed with zymography sample buffer (Bio-Rad, CA, USA), incubated for $1 \mathrm{~h}$ at room temperature, and analyzed by SDS-PAGE with $10 \%$ gels containing $1 \mathrm{mg} / \mathrm{ml}$ gelatin at $4{ }^{\circ} \mathrm{C}$. Proteins in the gels were renatured by incubating for $30 \mathrm{~min}$ at $37^{\circ} \mathrm{C}$ in $50 \mathrm{mM} \mathrm{Tris}-\mathrm{HCl} / \mathrm{pH}$

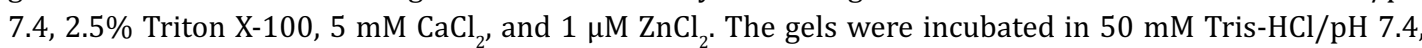
$5 \mathrm{mM} \mathrm{CaCl}_{2}$, and $1 \mu \mathrm{M} \mathrm{ZnCl}_{2}$ overnight at $37^{\circ} \mathrm{C}$. The gels were then stained with $0.25 \%(\mathrm{w} / \mathrm{v})$ Coomassie Brilliant Blue R250 solution in 20\% methanol and 5\% acetic acid, and destained in 20\% methanol and 5\% acetic acid.

\section{Preparation of cell lysates and Western blotting analysis}

Cells in serum-free DMEM were treated with statins and/or LPS for $40 \mathrm{~min}$ or otherwise indicated, lysed by adding high salt cell lysis buffer (20 mM Tris-HCl/pH 7.5, 1 mM EDTA, 1 mM EGTA, 1\% Triton X-100, $1 \mathrm{mg} / \mathrm{ml}$ leupeptin, $2.5 \mathrm{mM}$ sodium pyrophosphate, $1 \mathrm{mM}$ beta-glycerophosphate, $1 \mathrm{mM} \mathrm{Na} \mathrm{VO}_{4}, 0.3 \mathrm{M} \mathrm{NaCl}$, $0.5 \mathrm{mM}$ phenylmethanesulfonyl fluoride) plus phosphatase inhibitor cocktail, and centrifuged at 12,000 $\mathrm{x}$ $g$ for $5 \mathrm{~min}$ at $4^{\circ} \mathrm{C}$. Total cell lysates separated by SDS-PAGE was processed for Western blot analyses using enhanced chemiluminescence detection kit.

\section{Statistical analysis}

Data are presented as mean \pm standard deviation (SD). Statistical comparison of data was determined using one-way analysis of variance, followed by the Dunnett post-hoc adjustment. A value of $P<0.05$ was considered significant.

\section{Results}

Atorvastatin and simvastatin up-regulate LPS-induced MMP-9 gene expression

Quantitative real-time PCR and zymography assays showed that LPS $(0.1 \mu \mathrm{g} / \mathrm{ml})$ induced gene expression of MMP-9 in RAW 264.7 macrophages. Treatment of cells with 
Lee/Park/Kim et al.: Distinct Effects of Various Statins on LPS-induced MMP-9 Expression

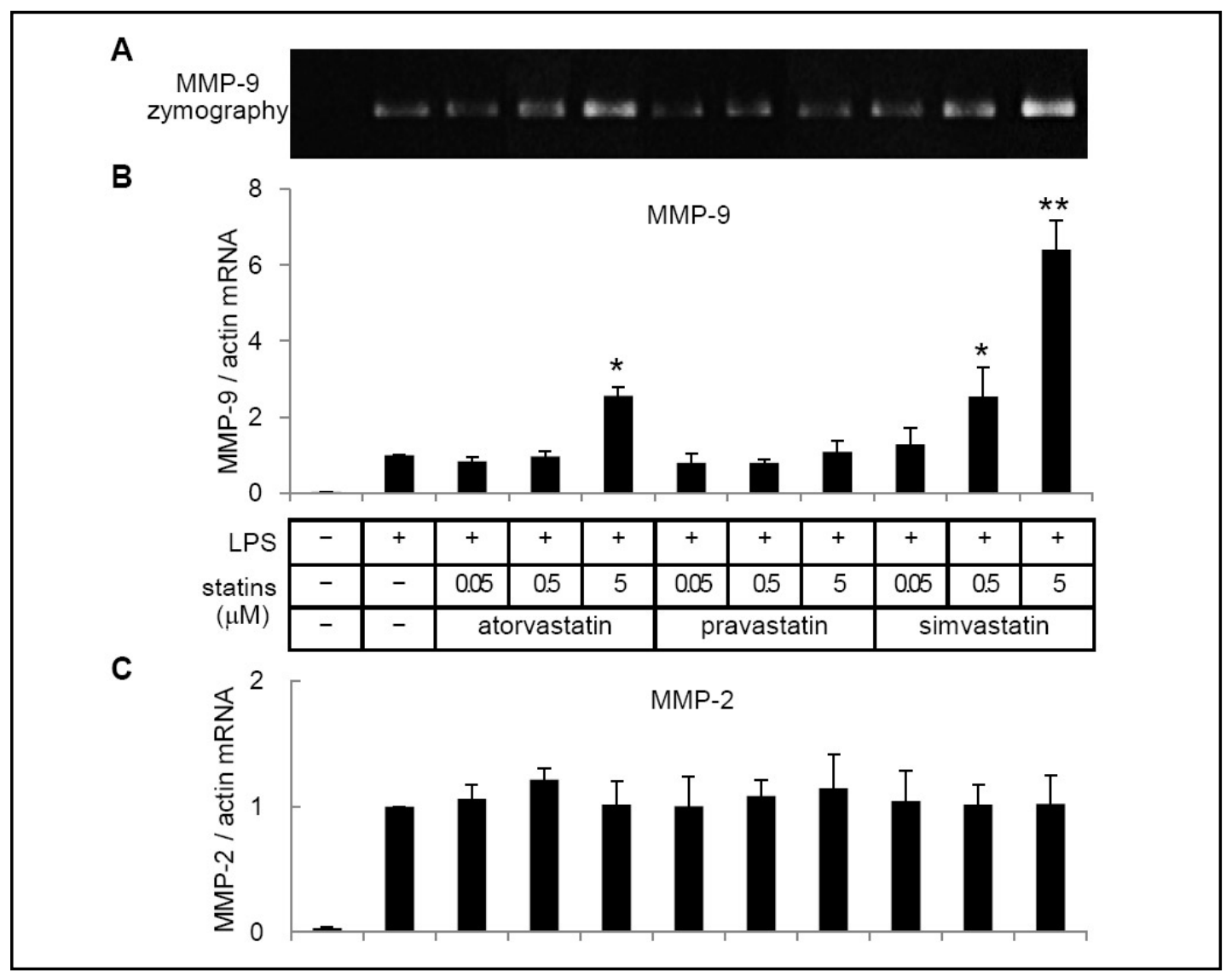

Fig. 1. Atorvastatin and simvastatin up-regulate LPS-induced MMP-9 gene expression in a dose dependent manner. RAW 264.7 cells were treated with LPS $(0.1 \mu \mathrm{g} / \mathrm{ml})$ and/or various concentrations of atorvastatin, pravastatin, and simvastatin for $16 \mathrm{hrs}$. Final concentrations of DMSO in all cell culture treatments were adjusted to $0.05 \%$. Zymography (A) of media was carried out as described in the Method section. Real-time RT-PCR of MMP-9 (B) was carried out with $\beta$-actin as an internal control. Ratios of MMP-9 mRNA to $\beta$-actin mRNA in the presence of LPS without statins were calculated as 1 in each set of experiments for statistical analysis. Results are presented as means $\pm \mathrm{SD} ; \mathrm{n}$ (numbers of experiments performed) $=4 .^{*} p<0.01 v s$ LPS only. ${ }^{* *} p<0.001 v s$ LPS only. Statistical comparison of data was determined using one-way ANOVA followed by the Dunnett posttest adjustment. Real-time RT-PCR of MMP-2 (C) was carried out with $\beta$-actin as an internal control as described above.

atorvastatin or simvastatin, unlike pravastatin treatment, significantly enhanced LPS-induced MMP-9 gene expression (Fig. 1A and B). Effects of vehicle (DMSO) on LPS-induced MMP-9 gene expression could be excluded, since final concentrations of DMSO in all cell culture experiments were adjusted to $0.05 \%$. While simvastatin up-regulated LPS-induced MMP-9 gene expression approximately two-fold at $0.5 \mu \mathrm{M}$, atorvastatin did it at $5 \mu \mathrm{M}$. Zymography showed an enhanced expression of MMP-9 by atorvatatin or simvastatin at the protein level as well. Unlike MMP-9 gene expression, atorvastatin and simvastatin did not enhance MMP2 mRNA expression (Fig. 1C). Up-regulation of LPS-induced MMP-9 gene expression by atorvastatin and simvastatin was also observed in microglia BV2 cells (Fig. 2). Effects of the statins on LPS-induced MMP-9 gene expression were less pronounced in BV2 microglia than in RAW 264.7 macrophages. Statins at the concentrations used in this study neither changed the cell viability nor proliferation rate of the cells (data not shown). 
Lee/Park/Kim et al.: Distinct Effects of Various Statins on LPS-induced MMP-9 Expression

Fig. 2. Up-regulation of LPS-induced MMP-9 gene expression is also observed in BV 2 microglia. RAW 264.7 or BV 2 cells were treated with LPS and $5 \mu \mathrm{M}$ of atorvastatin, pravastatin, or simvastatin for 8 hrs. Ratios of MMP-9 mRNA to $\beta$-actin mRNA in the presence of LPS without statins were calculated as 1 in each set of experiments for statistical analysis. Results are presented as means $\pm \mathrm{SD}$; $\mathrm{n}$ (numbers of experiments performed) $=3 . * p<0.05 v s$ LPS only. ${ }^{* *} p<0.01$ vs LPS only.
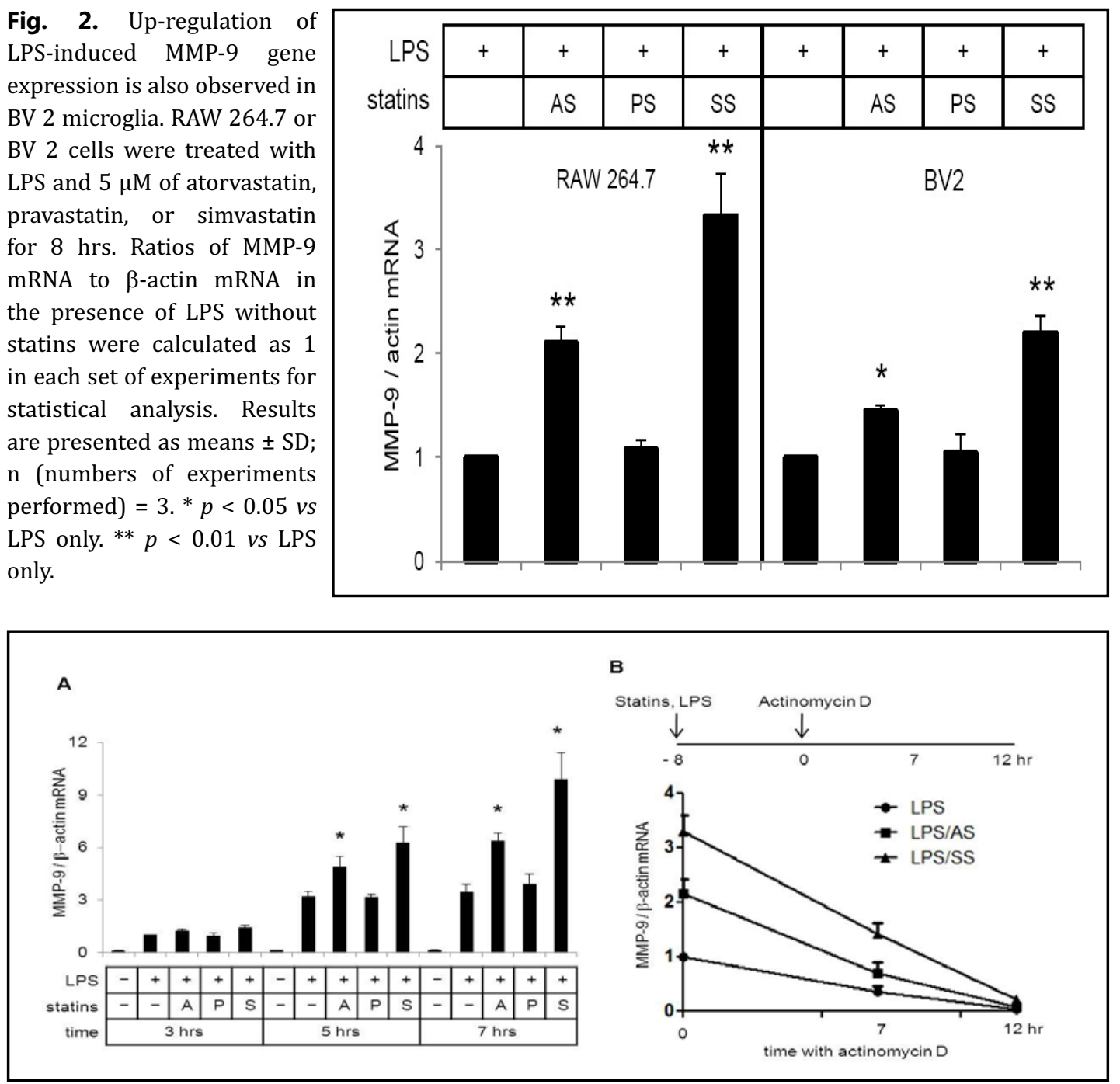

Fig. 3. Atorvastatin and simvastatin do not increase stability of MMP-9 mRNA. A, RAW 264.7 cells were incubated in media containing LPS and/or atorvastatin (A), pravastatin (P) or simvastatin (S) for given hours and subjected for RNA extraction. An amount of $\beta$-actin mRNA in each sample was used as a standard to determine relative abundance of MMP-9 mRNA. A ratio of MMP-9 expression to $\beta$-actin expression in the presence of LPS without statins for $3 \mathrm{hr}$ incubation was calculated as 1 in each set of experiments for statistical analysis. Results are presented as means $\pm \mathrm{SD} ; \mathrm{n}=3$ independent experiments. ${ }^{*} p<0.01$ vs LPS only. B, Cells were incubated in media containing LPS with or without atorvastatin (AS) or simvastatin (SS) for $8 \mathrm{hrs}$ before addition of actinomycin D $(2 \mu \mathrm{g} / \mathrm{ml})$ and further incubated as indicated. Real-time RT-PCR of MMP-9 was carried out with $\beta$-actin as an internal control to determine relative abundance of MMP-9 mRNA. Ratios of MMP-9 mRNA to $\beta$-actin mRNA at time $0 \mathrm{~h}$ of actinomycin D were calculated as 1 in each set of experiments for statistical analysis. Results are presented as means \pm SD; $n=3$ independent experiments.

\section{Atorvastatin and simvastatin do not increase stability of MMP-9 $\mathrm{mRNA}$}

An optimal time interval required for atorvastatin and simvastatin to initiate upregulation of MMP-9 gene expression was determined to explore mechanisms by which atorvastatin and simvastatin enhanced LPS-mediated MMP-9 gene expression. Up-regulation of LPS-induced MMP-9 mRNA expression by atorvastatin and simvastatin became statistically significant at $5 \mathrm{~h}$ after the treatment, and increasingly pronounced with the lapse of time (Fig. 3A). 
Lee/Park/Kim et al.: Distinct Effects of Various Statins on LPS-induced MMP-9 Expression

A

\begin{tabular}{|c|c|c|c|c|c|c|c|c|c|c|c|c|}
\hline LPS & + & + & + & + & + & + & + & + & + & + & + & + \\
\hline \multirow{2}{*}{$\begin{array}{r}\text { Time (hr) } \\
\text { statins }\end{array}$} & 0.5 & 1.5 & 3 & 0.5 & 1.5 & 3 & 0.5 & 1.5 & 3 & 0.5 & 1.5 & 3 \\
\hline & \multicolumn{3}{|c|}{-} & \multicolumn{3}{|c|}{ atorvastatin } & \multicolumn{3}{|c|}{ pravastatin } & \multicolumn{3}{|c|}{ simvastatin } \\
\hline
\end{tabular}

P-ERK $=-\ldots-\ldots-\ldots-\ldots$

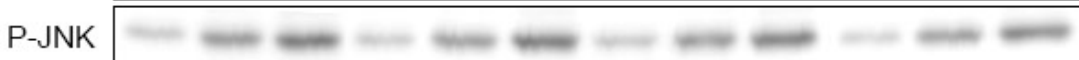

P-p38 $-\ldots-\ldots-\ldots-\ldots$

$\mathrm{lkB}-\ldots-\ldots-\ldots-\ldots$

B
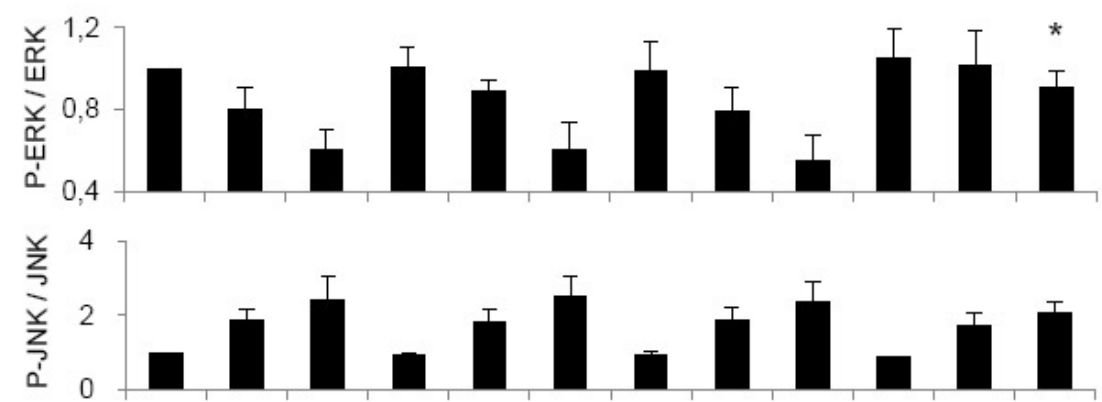

IIili,ilini,

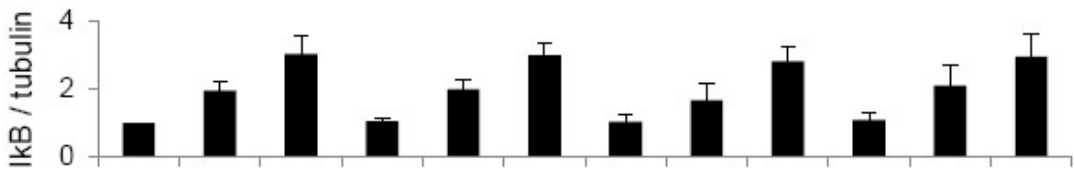

Fig. 4. Simvastatin extends duration of ERK phosphorylation. A, Cells in serum-free medium were stimulated with LPS $(0.1 \mu \mathrm{g} / \mathrm{ml})$ with or without $5 \mu \mathrm{M}$ statins for $0.5,1.5$, or $3 \mathrm{hrs}$. Whole cell lysates separated on SDSpolyacrylamide gels were analyzed with P-p38, p38, P-ERK 1/2, ERK 1/2, P-JNK, or JNK. Representative results out of 3 independent experiments are shown. B, Quantitation of protein levels of P-p38, P-ERK, and P-JNK was calculated with those of non-phosphorylated p38, ERK, and JNK, respectively. Ratios of protein levels of interest to those of non-phosphorylated forms obtained from cells incubated in the presence of LPS for $0.5 \mathrm{~h}$ were calculated as $1 \mathrm{in}$ each set of experiments for statistical analysis. Results are shown as means $\pm \mathrm{SD} ; \mathrm{n}=3$ independent experiments. ${ }^{*} p<0.05 v s$ LPS only.

We determined if atorvastatin or simvastatin changed stability of MMP-9 mRNA based on requirement of incubation of cells with statins for several hours for the up-regulation of LPS-induced MMP-9 gene expression by statins. Decay rates of the existing MMP-9 mRNA, after the LPS-induced expression had been modulated by statins, were analyzed by incubating the cells for $0-12 \mathrm{~h}$ with actinomycin D $(2 \mu \mathrm{g} / \mathrm{ml})$ to prevent the synthesis of a new RNA. Decay rates of MMP-9 mRNA in the presence of simvastatin or atorvastatin (slopes of the top and middle lines, respectively, in Fig. 3B) were not lower but slightly higher than in the absence of the drugs (bottom line). These results indicate that atorvastatin or simvastatin 


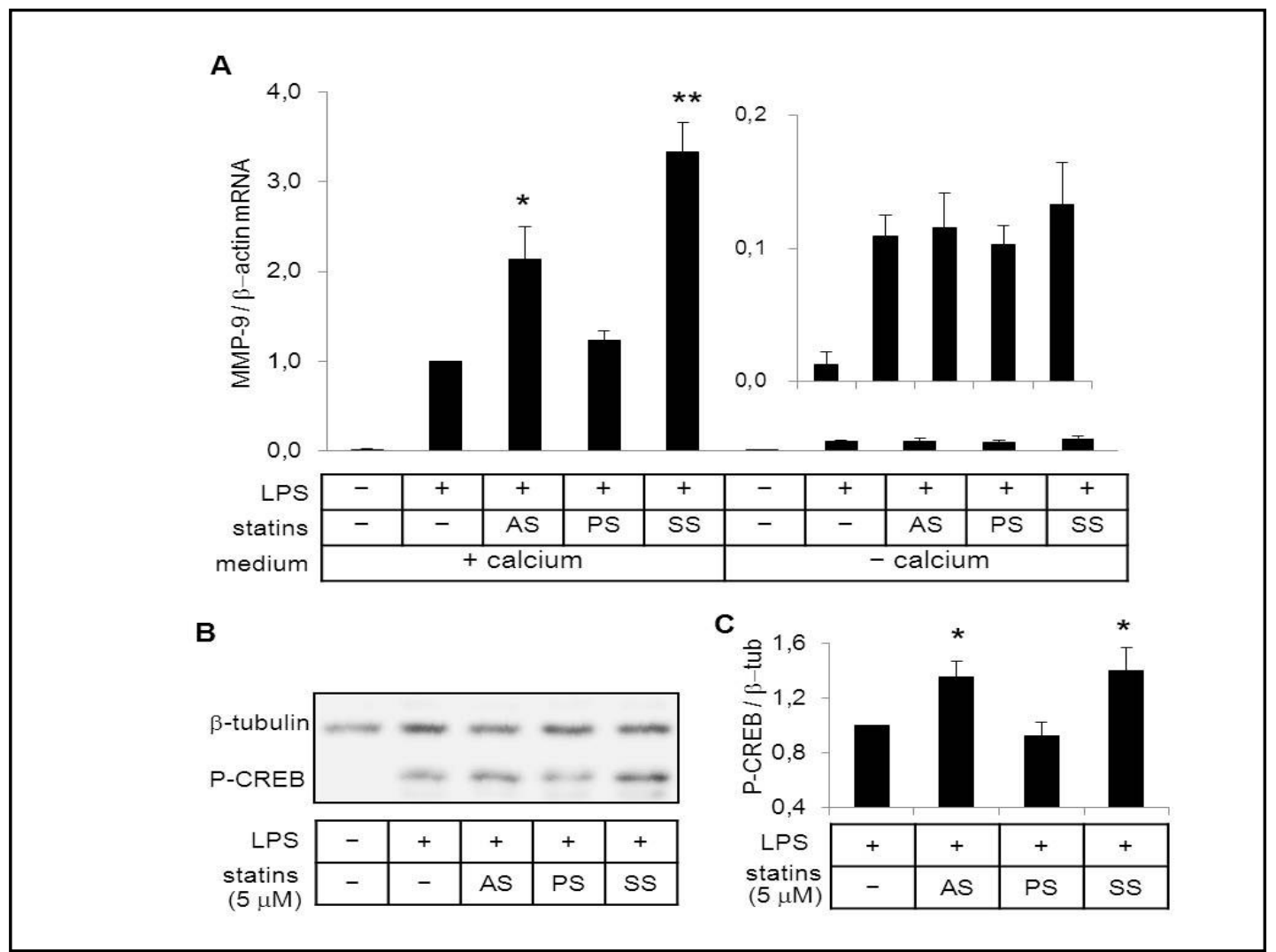

Fig. 5. Up-regulation of LPS-induced MMP-9 gene expression is dependent on calcium ion. A, Cells were treated with LPS and $5 \mu \mathrm{M}$ of atorvastatin (AS), pravastatin (PS), or simvastatin (SS) in regular medium (+ calcium) or calcium free medium (- calcium) and subjected to RNA extraction. A ratio of MMP-9 to $\beta$-actin mRNA in the presence of LPS without statins in regular medium was calculated as $1 .{ }^{*} p<0.01$ vs LPS only. ${ }^{* *} p<0.001 v s$ LPS only. B, Total cell extracts prepared from cells incubated with LPS and statins $(5 \mu \mathrm{M})$ for 4 hrs were analyzed by Western blot assay. (C) Quantitation of protein levels of P-CREB was calculated with beta-tubulin on the same gels as an internal control. Ratios of protein levels of P-CREB to beta-tubulin obtained from cells incubated in the presence of LPS for $4 \mathrm{~h}$ were calculated as 1 in each set of experiments for statistical analysis. Results are shown as means $\pm \mathrm{SD} ; \mathrm{n}=3$ independent experiments. $* p<0.01$ vs LPS only.

did not decrease, but rather slightly increased the decay rate of MMP-9 mRNA. In summary, atorvastatin and simvastatin do not up-regulate LPS-mediated MMP-9 gene expression by stabilizing MMP-9 mRNA.

Simvastatin extends phosphorylation duration of extracelluar signal kinases (ERK)

Treatment of RAW 264.7 cells with LPS resulted in phosphorylation and activation of the MAP kinases p38, ERK1/2, and c-Jun N-terminal kinases (JNK), which play a key role in activation of AP-1 family transcription factors to induce MMP-9 gene expression [9]. Cotreatment with atorvastatin or simvastatin at various concentrations did not enhance the initial phosphorylation degree of p38, ERK1/2, or JNK at $30 \mathrm{~min}$ (data not shown). We, therefore, analyzed whether statins could regulate activities of the kinases by changing duration of phosphorylation. Effects of the statins on phosphorylation degree of MAP kinases were analyzed from 0.5 to $3 \mathrm{~h}$ after treatment with LPS and statins. The amounts of phosphorylated ERK from cells treated with LPS gradually decreased with the lapse of time from 0.5 to $3 \mathrm{~h}$ (Fig. 4). Atorvastatin and pravastatin showed little effect on phosphorylation 
A

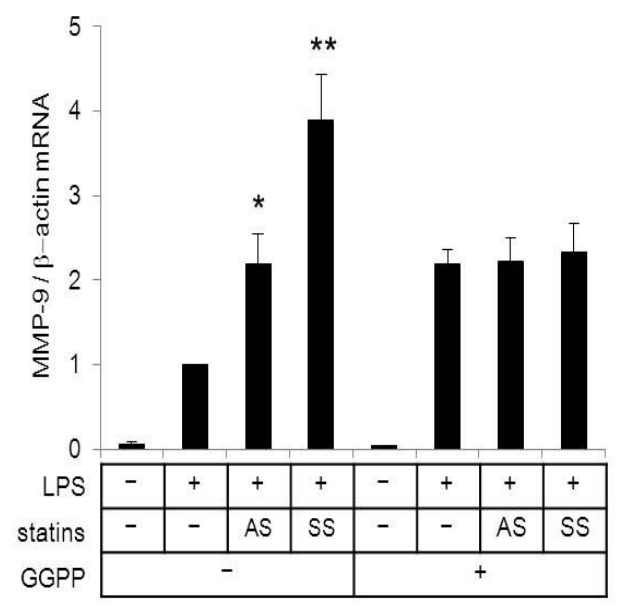

B

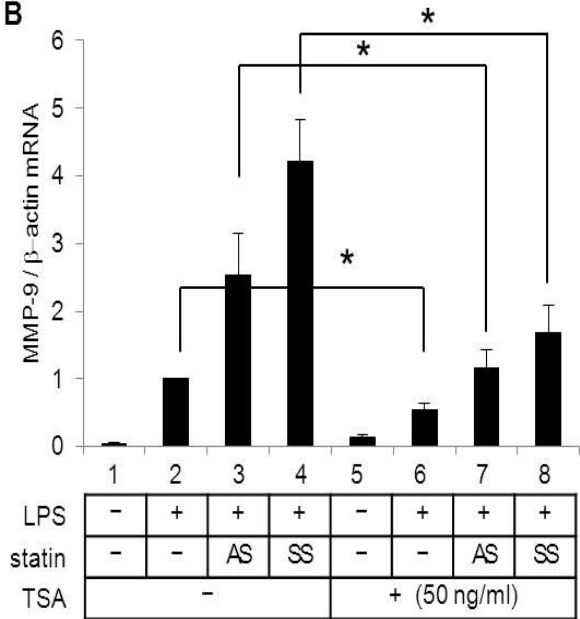

Fig. 6. Addition of GGPP or TSA suppresses the up-regulation of LPS-induced MMP-9 gene expression by atorvastatin or simvastatin. A, Cells were incubated in media containing $0.1 \mu \mathrm{g} / \mathrm{ml}$ LPS and with or without $5 \mu \mathrm{M}$ atorvastatin (AS) or simvastatin (SS). GGPP (final concentration $15 \mu \mathrm{M}$ ) was added to cell culture wells as indicated. A ratio of MMP-9 to $\beta$-actin mRNA in the presence of LPS without statins and GGPP was calculated as 1 and used as a standard to compare statin effects with or without GGPP. Results are presented as means $\pm \mathrm{SD} ; \mathrm{n}=3$ independent experiments. ${ }^{*} p<0.01$ vs LPS only. ${ }^{* *} p<0.001$ vs LPS only. B, Cells were treated with LPS and with or without $5 \mu \mathrm{M}$ atorvastatin (AS) or simvastatin (SS). TSA was added to cell culture wells as indicated. A ratio of MMP-9 to $\beta$-actin mRNA in the presence of LPS without statins and TSA was calculated as 1 and used as a standard to compare statin treatment groups in experiments with or without TSA. Results are presented as means \pm SD; $\mathrm{n}=3$ independent experiments. ${ }^{*} p<0.01$.

degree of ERK induced by LPS. However, the amount of phosphorylated ERK did not significantly decrease at $1.5 \mathrm{~h}$ and slightly decreased at $3 \mathrm{~h}$ after the treatment with LPS and simvastatin (Fig. 4).

In contrast to the phosphorylation degree of ERK, phosphorylation degrees of JNK as well as p38 were not changed by atorvastatin or simvastatin (Fig. 4B). In addition, treatment with the statins did not change the amounts of IкB (Fig. 4B), indicating that atorvastatin and simvastatin do not enhance LPS-induced MMP-9 gene expression by modulating NFKB activity.

Up-regulation of LPS-induced MMP-9 gene expression by atorvastatin or simvastatin is dependent on extracellular calcium ion, and mediated by phosphorylation of CREB

Based on the correlation between induction of influx of extracellular calcium ion by LPS and gene expression of proinflammatory cytokines $[12,27]$, we analyzed if up-regulation of LPS-induced MMP-9 gene expression by atorvastatin or simvastatin was dependent on calcium ions in the media. LPS could induce MMP-9 gene expression regardless of the presence of calcium ions in the media, although the expression level was much lower in the media without calcium ions (Fig. 5A). However, up-regulation of LPS-induced MMP-9 expression by atorvastatin or simvastatin was not observed in the calcium ion-free media (inlet figure of Fig. 5A).

Given the reports that phosphorylation of CREB at residue 133, which is triggered by calcium ion or cAMP [11], induces expression of MMP-9 [28], we determined whether atorvastatin or simvastatin modulates phosphorylation degree of CREB. For accurate quantitation, intensities of phosphorylated CREB (MW $43 \mathrm{kD}$ ) were compared with those of $\beta$-tubulin (MW $55 \mathrm{kD}$ ) on the same gels. In line with the report [29], LPS induced 
phosphorylation of CREB (Fig. 5B), which was further enhanced by $5 \mu \mathrm{M}$ atorvastatin or simvastatin, but not by $5 \mu \mathrm{M}$ pravastatin (Fig. $5 \mathrm{~B}$ and C).

\section{GGPP suppresses the up-regulation of LPS-mediated MMP-9 gene expression by atorvastatin and simvastatin}

Statins inhibit the conversion of HMG-Co A to mevalonate that acts not only as a precursor for cholesterol synthesis but also as an intermediate metabolite for protein prenylation. The addition of $15 \mu \mathrm{M}$ GGPP, an intermediate metabolite of the cholesterol synthesis pathway, enhanced LPS-induced MMP-9 mRNA expression approximately two-fold (Fig. 6A). Contrary to the control group, where GGPP was not added, atorvastatin and simvastatin did not further up-regulate LPS-induced MMP-9 gene expression when $15 \mu \mathrm{M}$ GGPP was added. Upregulation of LPS-induced MMP-9 gene expression by $20 \mu \mathrm{M}$ atorvastatin, which was similar to the induction fold by $5 \mu \mathrm{M}$ simvastatin, was also suppressed with the addition of $15 \mu \mathrm{M}$ GGPP (data not shown).

HDAC inhibitor down-regulates LPS-induced MMP-9 gene expression

Recent studies have reported that histone deacetylase (HDAC) inhibitor, trichostatin A (TSA), suppresses LPS-induced gene expression of interleukin-1, tumor necrosis factor $\alpha$, and nitric oxide synthase in macrophages [30,31]. Thus, we investigated if TSA could also suppress the statin-mediated up-regulation of LPS-induced MMP-9 gene expression. Treatment of cells with TSA suppressed LPS-induced MMP-9 gene expression in the absence or presence of the statins (Fig. 6B). However, the ratios of LPS-induced MMP-9 mRNA expression in the presence of atorvastatin or simvastatin to those in the absence of statins did not change with TSA treatment.

\section{Discussion}

To our knowledge, this is the first study to report that atorvastatin and simvastatin, but not pravastatin, up-regulated LPS-induced MMP-9 gene expression in RAW 264.7 macrophages and BV2 microglia.

The half maximal inhibitory concentration $\left(\mathrm{IC}_{50}\right)$ of atorvastatin, pravastatin, and simvastatin to inhibit HMG-CoA reductase are 5, 23, and $95 \mathrm{nM}$, respectively [32, 33]. Differences in $\mathrm{IC}_{50}$ values of the statins to inhibit HMG-CoA reductase may not explain distinct effects of the statins on LPS-induced MMP-9 gene expression. First, less than 5 fold difference of $\mathrm{IC}_{50}$ values between pravastatin $(23 \mathrm{nM})$ and simvastatin $(95 \mathrm{nM})$ cannot explain their different effects on LPS-induced MMP-9 gene expression observed in this study. Second, while the concentration of atorvastatin required to up-regulate LPS-induced MMP-9 gene expression $(5 \mu \mathrm{M})$ is approximately thousand-fold higher than its IC50 $(5 \mathrm{nM})$, that of simvastatin $(0.5 \mu \mathrm{M})$ is approximately five-fold higher than its IC50 $(95 \mathrm{nM})$.

Thus, we considered other potential molecular mechanisms to explain the up-regulation of LPS-induced MMP-9 gene expression by atorvastatin or simvastatin: increasing MMP-9 mRNA stability, and enhancing activity of transcription factors involved in MMP-9 mRNA expression by changing phosphorylation degree of CREB and/or the kinases involved in activation of the AP-1 family transcription factors.

\section{MMP-9 mRNA stability}

It has been reported that nitric oxide suppressed the expression of HuR, an mRNA stabilizing factor interacting with the AU-rich elements in the 3' untranslated region, and increased the decay rate of MMP-9 mRNA in glomerular mesangial cells [34]. In the present study, atorvastatin and simvastatin did not decrease but slightly increased the decay rate 
of MMP-9 mRNA, indicating that these drugs did not up-regulate LPS-induced MMP-9 gene expression by increasing MMP-9 mRNA stability.

\section{ERK phosphorylation}

A number of plant extracts, such as epigallocatechin gallate from green tea and curcumin from curry, have been reported to suppress NFKB and/or AP-1 by changing phosphorylation efficiency of IKB and/or kinases in the MAP kinase signaling pathway [35, 36]. Although the statins did not alter initial phosphorylation efficiency of the MAP kinases involved in activation of AP-1 family transcription factors, simvastatin increased duration of phosphorylation of ERK. The effect of atorvastatin on the extended duration of ERK phosphorylation was less pronounced. Pravastatin changed neither the degree of the initial phosphorylation nor the duration of phosphorylation of the kinase. This suggests that up-regulation of LPS-induced MMP-9 gene expression by simvastatin may be in part due to the extended time of ERK phosphorylation.

\section{Extracellular calcium and CREB phosphorylation}

Calcium ion overload due to enhanced influx of extracellular calcium ion has been reported to activate inflammatory signaling pathways [37] and cause ischemic brain damage that could be attenuated by inhibiting calcium influx [38, 39]. We showed that extracellular calcium ions were required for maximum induction of MMP-9 gene expression by LPS, which is in line with the study using neutrophils demonstrating that $\mathrm{cAMP} / \mathrm{Ca}^{2+}$ pathway is involved in LPS-induced MMP-9 secretion [40]. We also showed that extracellular calcium ions were necessary for up-regulation of LPS-induced MMP-9 gene expression by atorvastatin and simvastatin. In the following experiments, which were performed after consideration of the reports that phosphorylation and activation of CREB were mediated by calcium ions, we demonstrated that atorvastatin and simvastatin changed phosphorylation efficiency of CREB, linking the CREB-related pathways to the statin-mediated up-regulation of LPSinduced MMP-9 gene expression. In conclusion, simvastatin enhanced phosphorylation degree of CREB and ERK, whereas atorvastatin enhanced that of CREB, which would explain the more pronounced effect on LPS-induced MMP-9 gene expression by simvastatin.

Lipophilic atorvastatin and simvastatin intercalate into the upper hydrocarbon core of the lipid bilayer, while hydrophilic pravastatin interacts with the polar surface of the membrane [41]. Further studies are required to see if a lipophilicity-related differential modulation of membraine calcium channels by atorvastatin and simvastatin vs. pravastatin could affect LPS-induced influx of extracellular calcium ion and consequently CREB phosphorylation, followed by differential expression of MMP-9 gene.

\section{Suppression of statin-mediated up-regulation of LPS-induced MMP-9 expression}

Trying to reverse the effect of atorvastatin and simvastatin, we investigated the effect of GGPP, which is a precursor for cholesterol synthesis and an intermediate metabolite for protein prenylation. Atorvastatin and simvastatin failed to up-regulate LPS-induced MMP-9 gene expression after the addition of GGPP. Isoprenoids produced from mevalonate, such as GGPP or farnesyl pyrophosphate, initiate post-translational prenylation of Rac and Ras homologue (RHO) which enables small GTPase proteins to associate with membrane for biological function [15]. Inhibition of translocation of Rac-1 GTPase results in attenuation of NADPH-mediated free radical production. Although inhibition of prenylation of proteins, especially small GTPases, has been reported to play a role in most pleiotropic effects of statins [16], it appears to result in up-regulation of LPS-induced MMP-9 gene expression by simvastatin.

Biochemical and molecular analyses of MMP-9 gene expression in HeLa cells using chromatin immunoprecipitation and transient transfection assays demonstrated that 


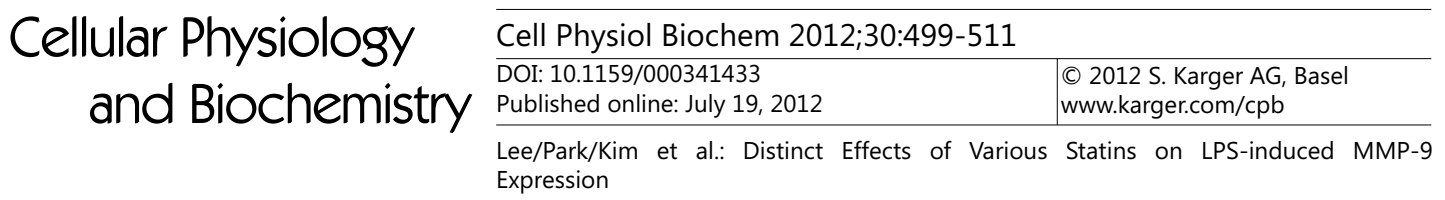

Fig. 7. A schematic diagram explains mechanisms by which atorvastatin and simvastatin up-regulate LPSinduced MMP-9 gene expression. An italic letter $p$ represents phosphorylation. Interaction of LPS with the CD14/toll-like receptor 4 (TLR4) complexes on the cell surface does not only stimulate phosphorylation of the MAP kinases but also induce influx of calcium ions into cells. Atorvastatin enhances the phosphorylation degree of CREB, whereas simvastatin enhances the phosphorylation degree of both ERK and CREB.

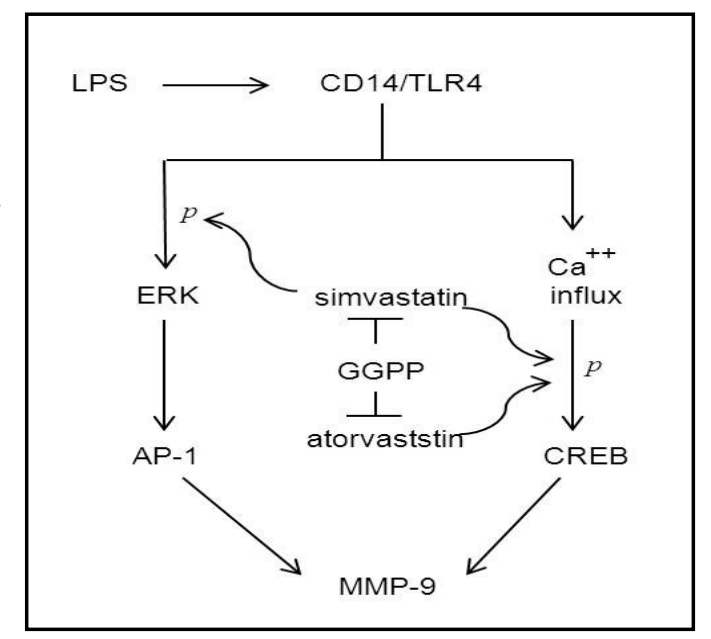

HDAC-1 and HDAC-3, but not HDAC-2 and HDAC-4, participate in transcriptional regulation of MMP-9 [42]. TSA belongs to a class I HDAC inhibitor that blocks the activity of HDAC1, HDAC-2, HDAC-3, and HDAC-8 [43]. Our result showing that treatment of cells with TSA reduced LPS-induced MMP-9 gene expression is in line with the report that TSA suppresses gene expression of inflammatory cytokines [30, 31, 44]. However, atorvastatin and simvastatin could up-regulate LPS-induced MMP-9 gene expression in the presence of TSA, demonstrating that the effects by atorvastatin and simvastatin do not result from regulating activity of HDAC- 1 or -3 .

\section{Conclusion}

We report on atorvastatin- and simvastatin-mediated up-regulation of LPS-induced MMP-9 expression in macrophages and microglia, reveal their mechanisms linked to the LPS - phosphorylation of ERK/CREB - MMP-9 signaling pathway, and introduce GGPP and TSA as inhibitors of the off-target effects of the statins (Fig. 6 and 7). Considering the clinical implications of the widely-prescribed statins as well as the importance of proper regulation of MMP-9 expression in the pathologic vs. physiologic remodeling [45], our study merits further investigation in clinical settings as well as in animal models, particularly in certain inflammatory conditions that are mediated by LPS.

\section{Acknowledgements}

The authors thank Dae Wui Kim, Ok Soo Kim, Jin Hyun Park for technical assistance, and Witek Kwiatkowski and Sung Ji Choi for careful reading the manuscript. This study was supported by a grant of the Korean Health Technology R\&D Project, Ministry for Health, Welfare \& Family Affairs (A101904) to Dong Kun Lee and Dong-Eog Kim and IFEZ. Disclosure: The authors declare no competing financial interests.

\section{References}

1 Zhao BQ Wang S, Kim HY, Storrie H, Rosen BR, Mooney DJ, Wang X, Lo EH: Role of matrix metalloproteinases in delayed cortical responses after stroke. Nat Med 2006;12:441-445.

2 Lim CS, Shalhoub J, Gohel MS, Shepherd AC, Davies AH: Matrix metalloproteinases in vascular disease--a potential therapeutic target? Curr Vasc Pharmacol 2010;8:75-85. 


\section{Cellular Physiology and Biochemistry}

3 Kim DE, Kim JY, Schellingerhout D, Kim EJ, Kim HK, Lee S, Kim K, Kwon IC, Shon SM, Jeong SW, Im SH, Lee DK, Lee MM, Kim GE: Protease imaging of human atheromata captures molecular information of atherosclerosis, complementing anatomic imaging. Arterioscler Thromb Vasc Biol 2010;30:449-456.

4 Shon SM, Park JH, Nahrendorf M, Schellingerhout D, Kim JY, Kang BT, Jeong SW, Kim EJ, Ryu JH, Kim K, Kwon IC, Lee DK, Lee MM, Kim DE: Exercise attenuates matrix metalloproteinase activity in preexisting atherosclerotic plaque. Atherosclerosis 2011;216:67-73.

5 Foronjy R, Nkyimbeng T, Wallace A, Thankachen J, Okada Y, Lemaitre V, D’Armiento J: Transgenic expression of matrix metalloproteinase-9 causes adult-onset emphysema in mice associated with the loss of alveolar elastin. Am J Physiol Lung Cell Mol Physiol 2008;294:L1149-1157.

6 Del Zoppo GJ, Frankowski H, Gu YH, Osada T, Kanazawa M, Milner R, Wang X, Hosomi N, Mabuchi T, Koziol JA: Microglial cell activation is a source of metalloproteinase generation during hemorrhagic transformation. J Cereb Blood Flow Metab 2012

7 Rouis M: Matrix metalloproteinases: A potential therapeutic target in atherosclerosis. Curr Drug Targets Cardiovasc Haematol Disord 2005;5:541-548.

8 Mackman N, Brand K, Edgington TS: Lipopolysaccharide-mediated transcriptional activation of the human tissue factor gene in thp-1 monocytic cells requires both activator protein 1 and nuclear factor kappa $\mathrm{b}$ binding sites. J Exp Med 1991;174:1517-1526.

9 Lin CC, Tseng HW, Hsieh HL, Lee CW, Wu CY, Cheng CY, Yang CM: Tumor necrosis factor-alpha induces mmp-9 expression via p42/p44 mapk, jnk, and nuclear factor-kappab in a549 cells. Toxicol Appl Pharmacol 2008;229:386-398.

10 Masure S, Nys G, Fiten P, Van Damme J, Opdenakker G: Mouse gelatinase b. Cdna cloning, regulation of expression and glycosylation in wehi-3 macrophages and gene organisation. Eur J Biochem 1993;218:129141.

11 Illario M, Giardino-Torchia ML, Sankar U, Ribar TJ, Galgani M, Vitiello L, Masci AM, Bertani FR, Ciaglia E, Astone D, Maulucci G, Cavallo A, Vitale M, Cimini V, Pastore L, Means AR, Rossi G, Racioppi L: Calmodulindependent kinase iv links toll-like receptor 4 signaling with survival pathway of activated dendritic cells. Blood 2008;111:723-731.

12 Zanoni I, Ostuni R, Capuano G, Collini M, Caccia M, Ronchi AE, Rocchetti M, Mingozzi F, Foti M, Chirico G, Costa B, Zaza A, Ricciardi-Castagnoli P, Granucci F: Cd14 regulates the dendritic cell life cycle after lps exposure through nfat activation. Nature 2009;460:264-268.

13 LaRosa JC, He J, Vupputuri S: Effect of statins on risk of coronary disease: A meta-analysis of randomized controlled trials. JAMA 1999;282:2340-2346.

14 Bu DX, Griffin G, Lichtman AH: Mechanisms for the anti-inflammatory effects of statins. Curr Opin Lipidol 2011;22:165-170.

15 Greenwood J, Steinman L, Zamvil SS: Statin therapy and autoimmune disease: From protein prenylation to immunomodulation. Nat Rev Immunol 2006;6:358-370.

16 Biasucci LM, Biasillo G, Stefanelli A: Inflammatory markers, cholesterol and statins: Pathophysiological role and clinical importance. Clin Chem Lab Med 2010;48:1685-1691.

17 Gargiulo S, Sottero B, Gamba P, Chiarpotto E, Poli G, Leonarduzzi G: Plaque oxysterols induce unbalanced up-regulation of matrix metalloproteinase- 9 in macrophagic cells through redox-sensitive signaling pathways: Implications regarding the vulnerability of atherosclerotic lesions. Free Radic Biol Med 2011;51:844-855.

18 Thompson PD, Clarkson P, Karas RH: Statin-associated myopathy. JAMA 2003;289:1681-1690.

19 Egan A, Colman E: Weighing the benefits of high-dose simvastatin against the risk of myopathy. N Engl J Med 2011;365:285-287.

20 Koh KK, Sakuma I, Quon MJ: Differential metabolic effects of distinct statins. Atherosclerosis 2011;215:1-8.

21 Anderson TJ, Meredith IT, Yeung AC, Frei B, Selwyn AP, Ganz P: The effect of cholesterol-lowering and antioxidant therapy on endothelium-dependent coronary vasomotion. N Engl J Med 1995;332:488-493.

22 Zeuke S, Ulmer AJ, Kusumoto S, Katus HA, Heine H: Tlr4-mediated inflammatory activation of human coronary artery endothelial cells by lps. Cardiovasc Res 2002;56:126-134.

23 Massaro M, Zampolli A, Scoditti E, Carluccio MA, Storelli C, Distante A, De Caterina R: Statins inhibit cyclooxygenase-2 and matrix metalloproteinase-9 in human endothelial cells: Anti-angiogenic actions possibly contributing to plaque stability. Cardiovasc Res 2010;86:311-320. 
24 Monick MM, Powers LS, Butler NS, Hunninghake GW: Inhibition of rho family gtpases results in increased tnf-alpha production after lipopolysaccharide exposure. J Immunol 2003;171:2625-2630.

25 Konat GW, Krasowska-Zoladek A, Kraszpulski M: Statins enhance toll-like receptor 4-mediated cytokine gene expression in astrocytes: Implication of rho proteins in negative feedback regulation. J Neurosci Res 2008;86:603-609.

26 Lee EJ, Kim HS: Inhibitory mechanism of mmp-9 gene expression by ethyl pyruvate in lipopolysaccharidestimulated bv2 microglial cells. Neurosci Lett 2011;493:38-43.

27 Zhou X, Yang W, Li J: $\mathrm{Ca}^{2+}$ - and protein kinase c-dependent signaling pathway for nuclear factor-kappab activation, inducible nitric-oxide synthase expression, and tumor necrosis factor-alpha production in lipopolysaccharide-stimulated rat peritoneal macrophages. J Biol Chem 2006;281:31337-31347.

28 Park JK, Park SH, So K, Bae IH, Yoo YD, Um HD: Icam-3 enhances the migratory and invasive potential of human non-small cell lung cancer cells by inducing mmp-2 and mmp-9 via akt and creb. Int J Oncol 2010;36:181-192.

29 Caivano M, Cohen P: Role of mitogen-activated protein kinase cascades in mediating lipopolysaccharidestimulated induction of cyclooxygenase- 2 and il-1 beta in raw264 macrophages. J Immunol 2000;164:3018-3025.

30 Adcock IM: Hdac inhibitors as anti-inflammatory agents. Br J Pharmacol 2007;150:829-831.

31 Yu Z, Zhang W, Kone BC: Histone deacetylases augment cytokine induction of the inos gene. J Am Soc Nephrol 2002;13:2009-2017.

32 Cohen LH, van Vliet A, Roodenburg L, Jansen LM, Griffioen M: Pravastatin inhibited the cholesterol synthesis in human hepatoma cell line hep g2 less than simvastatin and lovastatin, which is reflected in the upregulation of 3-hydroxy-3-methylglutaryl coenzyme a reductase and squalene synthase. Biochem Pharmacol 1993;45:2203-2208.

33 Gerber R, Ryan JD, Clark DS: Cell-based screen of hmg-coa reductase inhibitors and expression regulators using lc-ms. Anal Biochem 2004;329:28-34.

34 Akool el S, Kleinert H, Hamada FM, Abdelwahab MH, Forstermann U, Pfeilschifter J, Eberhardt W: Nitric oxide increases the decay of matrix metalloproteinase 9 mrna by inhibiting the expression of mrnastabilizing factor hur. Mol Cell Biol 2003;23:4901-4916.

35 Hosokawa Y, Hosokawa I, Ozaki K, Nakanishi T, Nakae H, Matsuo T: Catechins inhibit cxcl10 production from oncostatin m-stimulated human gingival fibroblasts. J Nutr Biochem 2009;21:659-664.

36 Bachmeier B, Nerlich AG, Iancu CM, Cilli M, Schleicher E, Vene R, Dell'Eva R, Jochum M, Albini A, Pfeffer $\mathrm{U}$ : The chemopreventive polyphenol curcumin prevents hematogenous breast cancer metastases in immunodeficient mice. Cell Physiol Biochem 2007;19:137-152.

37 Coultrap SJ, Vest RS, Ashpole NM, Hudmon A, Bayer KU: Camkii in cerebral ischemia. Acta Pharmacol Sin 2011;32:861-872.

38 Domercq M, Perez-Samartin A, Aparicio D, Alberdi E, Pampliega 0, Matute C: P2x7 receptors mediate ischemic damage to oligodendrocytes. Glia 2010;58:730-740.

39 Davidson JO, Green CR, Nicholson LF, O'Carroll SJ, Fraser M, Bennet L, Gunn AJ: Connexin hemichannel blockade improves outcomes in a model of fetal ischemia. Ann Neurol 2012;71:121-132.

40 Ernens I, Rouy D, Velot E, Devaux Y, Wagner DR: Adenosine inhibits matrix metalloproteinase- 9 secretion by neutrophils: Implication of a2a receptor and camp/pka/ca ${ }^{2+}$ pathway. Circ Res 2006;99:590-597.

41 Mason RP, Walter MF, Day CA, Jacob RF: Intermolecular differences of 3-hydroxy-3-methylglutaryl coenzyme a reductase inhibitors contribute to distinct pharmacologic and pleiotropic actions. Am J Cardiol 2005;96:11F-23F.

42 Ma Z, Shah RC, Chang MJ, Benveniste EN: Coordination of cell signaling, chromatin remodeling, histone modifications, and regulator recruitment in human matrix metalloproteinase 9 gene transcription. Mol Cell Biol 2004;24:5496-5509.

43 Dokmanovic M, Clarke C, Marks PA: Histone deacetylase inhibitors: Overview and perspectives. Mol Cancer Res 2007;5:981-989.

44 Leoni F, Fossati G, Lewis EC, Lee JK, Porro G, Pagani P, Modena D, Moras ML, Pozzi P, Reznikov LL, Siegmund B, Fantuzzi G, Dinarello CA, Mascagni P: The histone deacetylase inhibitor itf2357 reduces production of pro-inflammatory cytokines in vitro and systemic inflammation in vivo. Mol Med 2005;11:1-15.

45 Rosell A, Lo EH: Multiphasic roles for matrix metalloproteinases after stroke. Curr Opin Pharmacol 2008;8:82-89. 